\title{
Second to fourth digit ratio: its relationship with core cancer volume and Gleason score in prostate biopsy
}

\author{
Jin Kyu Oh, Khae Hawn Kim, Han Jung, Sang Jin Yoon, Tae Beom Kim \\ Department of Urology, Gachon University Gil Hospital, Incheon, Republic of Korea
}

\section{ABSTRACT}

Objective: To investigate the relationships between 2 nd to 4 th digit ratio (digit ratio) and prostate cancer detection rate and biopsy findings, including Gleason score.

Materials and Methods: In 770 consecutive men aged 40 years or older that presented with lower urinary tract symptoms (LUTS), right hand 2nd and 4th digit lengths were measured prior to PSA determinations, DRE and transrectal ultrasonography (TRUS). Among these, 166 men with a prostate specific antigen (PSA) level $\geq 3 \mathrm{ng} / \mathrm{mL}$ or abnormal digit rectal examination (DRE) prospectively underwent prostate biopsies. The relationship between digit ratio and prostate cancer detection rate and biopsy findings was investigated.

Results: The study subjects were allocated to two groups by digit ratio (group A: digit ratio $<0.95 ; \mathrm{n}=420$; group $\mathrm{B}$ : digit ratio $\geq 0.95 ; \mathrm{n}=350$ ). Despite similar biopsy rates (22.4\% vs. $20.6 \%, p=0.544)$, group A had higher cancer detection rate (46.8\% (44/94) vs. $23.6 \%$ (17/72), $\mathrm{p}=0.002 ; \mathrm{OR}=2.847,95 \% \mathrm{CI}=1.445-5.610)$. When we analyzed 408 positive biopsy cores (group A: digit ratio $<0.95, \mathrm{n}=282$; group $\mathrm{B}$ : digit ratio $\geq$ $0.95, n=126$ ), group A had higher percentage of core cancer volume (46.7\% vs. 37.1\%, $\mathrm{p}=0.005$ ) and more biopsy cores with high Gleason score (sum of Gleason score $\geq 9$ : $18 / 282(6.4 \%)$ vs. $1 / 126(0.8 \%), p=0.010$; primary Gleason score $=5: 12 / 282(4.3 \%)$ vs. $0 / 126(0.0 \%), p=0.021)$.

Conclusions: A lower digit ratio is related to an increased detection rate of prostate cancer, a high percentage of core cancer volume and a high Gleason score.
ARTICLE INFO

Key words:

Gleason score; Prostate;

Biopsy; Prostatic Neoplasms

Int Braz J Urol. 2012; 38: 611-9

Submitted for publication:

March 16, 2012

Accepted after revision:

June 26, 2012

\section{INTRODUCTION}

The ratio of the 2 nd to 4 th digit length (digit ratio) of the right hand is known to be fixed in utero (1-3), and is sexually dimorphic and lower in men than in women (4-6). The digit ratio is negatively related to prenatal testosterone and positively related to prenatal estrogen concentrations (7).

The digit ratio of the right hand is related to the activity of the androgen receptor (AR) (8). Manning and colleagues demonstrated that the digit ratio of the right-hand is positively cor- related with the CAG repeat number of the AR gene, and that individuals with a low digit ratio possess AR alleles with low CAG repeat numbers (8). It has been well established that a low AR CAG repeat number increases the risks of prostate cancer $(9,10)$.

It has recently been suggested that the digit ratio is related to prostate specific antigen (PSA) level and the prostate cancer risk (11).

Based on the above-mentioned evidence, we thought that if digit ratio is related to the prostate cancer risk, digit ratio might be related to the detection rate of prostate biopsies and the 
biopsy findings including the indices of tumor volume (i.e., the number of cores involved and the percentage of cores involved) and Gleason score. We investigated the relationship between digit ratio and prostate cancer detection rate and biopsy findings.

\section{MATERIALS AND METHODS}

Among the men that presented with lower urinary tract symptoms (LUTS) at a single tertiary academic center, 770 consecutive men aged 40 years or older were prospectively enrolled. All patients in the present study come from a same ethnic Korean group.

Right hand 2nd and 4th digit lengths were measured by an investigator prior to the PSA determinations and digit rectal examination (DRE) and transrectal ultrasonography (TRUS). The digit lengths were measured directly on the ventral surface of the fingers using a digital vernier calliper (6); this measurement has been previously reported to provide a high degree of repeatability $(12,13)$. To minimize measurement errors, the mean values of duplicate measurements were used in the analysis.

Among 770 men, 166 men with a PSA level $\geq 3 \mathrm{ng} / \mathrm{mL}$ or abnormal DRE findings underwent a 12 core prostate biopsy as an initial biopsy. Biopsies were performed transrectally using an 18-gauge biopsy needle and a biopsy gun under TRUS guidance to provide the $17 \mathrm{~mm}$ long tissue cores.

The study subjects were allocated into two groups by digit ratio. As noted in previous study (11), we chose 0.95 as the cut-off value because the mean and median values of digit ratio of all patients $(\mathrm{n}=770)$ were 0.948 and 0.946 .

The cancer detection rates and biopsy findings were analyzed according to digit ratio. Student's t-test and Chi-square test were used to compare the variables of the two study groups, which were divided by digit ratio. To identify the independent predictive factors influencing prostate cancer detection, univariate and multivariate analysis were performed using logistic regression model. The analysis was performed using SPSS 12.0 (SPSS, Chicago, IL), and differences were considered statistically significant when the $\mathrm{P}$ values were less than 0.05 .

\section{RESULTS}

The patients' characteristics are summarized in Table-1. The mean patients' age, testosterone level, prostate volume, PSA level and prostate specific antigen density (PSAD) were $61.4 \pm 10.4$ yrs (mean \pm SD), $453.64 \pm 167.45$ $\mathrm{ng} / \mathrm{dL}, 34.70 \pm 18.04 \mathrm{cc}, 3.96 \pm 11.98 \mathrm{ng} / \mathrm{mL}$ and $0.101 \pm 0.312 \mathrm{ng} / \mathrm{mL} / \mathrm{cc}$, respectively. The mean 2nd and 4th digit lengths and the mean digit ratio were $7.223 \pm 0.467 \mathrm{~cm}, 7.625 \pm 0.483$ $\mathrm{cm}$ and $0.948 \pm 0.043$, respectively. Among 770 men, only five men $(0.6 \%)$ had a family history of prostate cancer (first-degree relative) and 41 men (5.3\%) had abnormal DRE findings. Among 770 men, 166 men (21.6\%) underwent prostate biopsies and 61 men (7.9\%) were found to have

Table 1 - Characteristics of the studied population.

\begin{tabular}{lc}
\hline & Mean \pm SD \\
\hline Age (years) & $61.4 \pm 10.4$ \\
2nd digit length (cm) & $7.223 \pm 0.467$ \\
4th digit length (cm) & $7.625 \pm 0.483$ \\
Digit ratio & $0.948 \pm 0.043$ \\
PV (cc) & $34.70 \pm 18.04$ \\
PSA (ng/mL) & $3.96 \pm 11.98$ \\
PSAD (ng/mL/cc) & $0.101 \pm 0.312$ \\
Testosterone (ng/dL) & $453.64 \pm 167.45$ \\
Family history (\%) & $0.6 \%(5 / 770)$ \\
Abnormal DRE (\%) & $5.3 \%(41 / 770)$ \\
Biopsy (\%) & $21.6 \%(166 / 770)$ \\
Cancer (\%) & $7.9 \%(61 / 770)$ \\
Cancer detection rate (\%) & $36.7 \%(61 / 166)$ \\
\hline
\end{tabular}

Digit ratio $=2$ nd digit length $/$ 4th digit length; $\mathbf{P V}=$ prostate volume; $\mathbf{P S A}=$ prostate specific antigen; $\mathbf{P S A D}=$ prostate specific antigen density; $\mathbf{D R E}=$ digital rectal examination. 
prostate cancer. Cancer detection rate of prostate biopsy was 36.7\% (61/166).

Besides age, PSA and DRE, univariate and multivariate analysis showed that digit ratio was also an independent predictor of prostate cancer detection (Table-2). digit ratio $\geq 0.95, \mathrm{n}=126$ ). Table 5 shows the relationships between digit ratio and biopsy findings. Group A had a higher percentage of core cancer volume $(46.69 \pm 31.73 \%$ vs. $37.07 \pm$ $29.43 \%, p=0.005)$ (Table-5). The distributions of the primary Gleason scores of the positive

Table 2 - Univariate and multivariate analysis using logistic regression model in biopsied patients $(\mathrm{N}=166)$.

\begin{tabular}{|c|c|c|c|c|c|c|}
\hline & & $\mathrm{Ca}$ & Non Ca & OR $(95 \% \mathrm{Cl})$ & $\begin{array}{l}\text { Univariate } \\
\text { p-value }\end{array}$ & $\begin{array}{c}\text { Multivariate } \\
\text { p-value }\end{array}$ \\
\hline Age (yrs) & $\geq 65$ & 51 & 67 & $\begin{array}{c}2.893 \\
(1.318-6.348)\end{array}$ & 0.007 & 0.013 \\
\hline & $<65$ & 10 & 38 & & & \\
\hline PSA (ng/mL) & $\geq 6$ & 46 & 45 & $\begin{array}{c}4.089 \\
(2.032-8.228)\end{array}$ & 0.000 & 0.009 \\
\hline & $<6$ & 15 & 60 & & & \\
\hline PV (cc) & $\geq 35$ & 41 & 74 & $\begin{array}{c}0.859 \\
(0.435-1.694)\end{array}$ & 0.660 & \\
\hline & $<35$ & 20 & 31 & & & \\
\hline URE & Abnormal & 29 & 12 & $\begin{array}{c}7.023 \\
(3.208-15.376)\end{array}$ & 0.000 & 0.000 \\
\hline \multirow{3}{*}{ Digit ratio } & Normal & 32 & 93 & & & \\
\hline & $<0.95$ & 44 & 50 & $\begin{array}{c}2.847 \\
(1.445-5.610)\end{array}$ & 0.002 & 0.003 \\
\hline & $\geq 0.95$ & 17 & 55 & & & \\
\hline
\end{tabular}

$\mathbf{C a}=$ cancer; $\mathbf{P S A}=$ prostate specific antigen; $\mathbf{P V}=$ prostate volume; $\mathbf{D R E}=$ digital rectal examination; $\mathbf{D i g i t}$ ratio $=$ 2nd digit length $/$ 4th digit length

The study subjects were allocated into two groups by digit ratio (group A: digit ratio < 0.95, $\mathrm{n}=420$; group $\mathrm{B}$ : digit ratio $\geq 0.95, \mathrm{n}=350$ ). Despite similar biopsy rates $(22.4 \%$ vs. $20.6 \%, \mathrm{p}=$ $0.544)$, group A had a higher cancer detection rate (46.8\% vs. $23.6 \%, p=0.002 ; \mathrm{OR}=2.847,95 \% \mathrm{CI}$ $=1.445-5.610)$. However, no intergroup difference was found for age, serum testosterone level, prostate volume, PSA, DRE findings, biopsy findings and clinical stage (Tables 3 and 4).

We analyzed the 408 positive biopsy cores (group $\mathrm{A}$ : digit ratio < 0.95, $\mathrm{n}=282$; group $\mathrm{B}$ : cores were different between the two groups (Table-5). Furthermore, in group A, a significantly greater proportion of cores were found to have Gleason scores $\geq 9(18 / 282(6.4 \%)$ vs. $1 / 126(0.8 \%), p=0.010)$ and primary Gleason score $=5(12 / 282(4.3 \%)$ vs. $0 / 126(0.0 \%), p=$ 0.021) (Table-5).

When we analyzed the 266 positive biopsy cores with the sum of Gleason scores $\geq 7$, the distributions of sum of Gleason scores as well as primary Gleason score were different between the two groups (Table-6). 
Table 3 - Comparison of the study variables between the two studied groups.

\begin{tabular}{lccc}
\hline & Digit ratio $<0.95$ & Digit ratio $\geq 0.95$ & p-value \\
\hline No of total patients & $\mathbf{4 2 0}$ & 350 & \\
Age (years) & $61.7 \pm 10.2$ & $61.0 \pm 10.6$ & 0.371 \\
Digit ratio & $0.919 \pm 0.024$ & $0.983 \pm 0.033$ & 0.000 \\
PV (cc) & $34.45 \pm 17.77$ & $34.99 \pm 18.37$ & 0.681 \\
PSA (ng/mL) & $4.41 \pm 12.78$ & $3.41 \pm 10.95$ & 0.248 \\
Abnormal DRE & $24 / 420(5.7 \%)$ & $17 / 350(4.9 \%)$ & 0.598 \\
Biopsy rate (\%) & $94 / 420(22.4 \%)$ & $72 / 350(20.6 \%)$ & 0.544 \\
No of biopsy patients & $\mathbf{9 4}$ & 72 & \\
Age (yrs) & $68.3 \pm 7.9$ & $69.2 \pm 9.0$ & 0.492 \\
Digit ratio & $0.918 \pm 0.024$ & $0.980 \pm 0.025$ & 0.000 \\
PV (cc) & $48.80 \pm 22.51$ & $51.23 \pm 26.16$ & 0.522 \\
PSA (ng/mL) & $16.34 \pm 23.42$ & $12.81 \pm 21.80$ & 0.323 \\
Abnormal DRE & $24 / 94(25.5 \%)$ & $17 / 72(23.6 \%)$ & 0.778 \\
Cancer detection rate (\%) & $44 / 94(46.8 \%)$ & $17 / 72(23.6 \%)$ & 0.002 \\
\hline
\end{tabular}

Digit ratio = 2nd digit length $/$ 4th digit length; $\mathbf{P V}=$ prostate volume; $\mathbf{P S A}=$ prostate specific antigen; $\mathbf{D R E}=$ digital rectal examination .

\section{DISCUSSION}

In humans, the growth and pattern of digits and the differentiation of gonads are controlled by the homeobox genes HOXA and HOXD $(2,13,14)$. Therefore, gonadal fetal products such as testosterone may influence finger morphology $(6,15,16)$. For example, a high concentration of testosterone, indicating high prenatal testicular activity leads to low digit ratio (17). Recently, Lutchmaya et al. (7) showed that digit ratio is negatively associated with prenatal testosterone levels and it is positively associated with prenatal estrogen levels.

It is well known that testosterone and androgen receptors (AR) play central roles in prostate growth and the development of prostate cancer. The short CAG repeat length of the androgen receptor gene (AR) has been reported to be associated with the aetiologies of prostate cancer $(9,10)$. Manning et al. (8) showed that the right-hand digit ratio is positively correlated with the CAG repeat number of AR.

Recently, Rahman et al. (18) reported that digit ratio is a reasonable marker for evaluation of prostate cancer risk. In their large casecontrol study, a higher digit ratio is related to more protective effect on prostate cancer risk, in particular, patients with age under 60 years. Considering these studies, it is highly suggestive that digit ratio may be related to prostate cancer.

In other study of the relationship between digit ratio and prostate cancer, Jung et al. (11) proposed that the 2 nd to 4 th digit ratio (digit ratio) of the right hand is related to PSA 
Table 4 - Comparison of the study variables between the two studied groups.

\begin{tabular}{lccc}
\hline & Digit ratio $<0.95$ & Digit ratio $\geq 0.95$ & p-value \\
\hline No of cancer patients & 44 & 17 & \\
Age (yrs) & $70.4 \pm 6.9$ & $72.7 \pm 8.6$ & 0.273 \\
Digit ratio & $0.921 \pm 0.021$ & $0.979 \pm 0.018$ & 0.000 \\
PV (cc) & $45.32 \pm 22.38$ & $46.99 \pm 19.62$ & 0.787 \\
PSA (ng/mL) & $26.84 \pm 30.63$ & $30.75 \pm 38.56$ & 0.679 \\
No of positive cores & $6.5 \pm 3.8$ & $7.4 \pm 3.6$ & 0.420 \\
Max core cancer vol (\%) & $56.83 \pm 34.08$ & $59.29 \pm 31.92$ & 0.815 \\
Max Sum of GS & $7.1 \pm 1.0$ & $7.1 \pm 1.0$ & 0.849 \\
Max Primary GS & $3.6 \pm 0.5$ & $3.6 \pm 0.5$ & 0.867 \\
Max Secondary GS & $3.5 \pm 0.7$ & $3.5 \pm 0.7$ & 0.880 \\
Clinical stage & & & 0.293 \\
CT1 & 15 & 2 & 6 \\
CT2 & 15 & 6 & \\
CT3 & 10 & 3 & \\
CT4 & 4 & 6 & \\
\hline
\end{tabular}

Digit ratio = 2nd digit length $/$ 4th digit length; $\mathbf{P V}=$ prostate volume; $\mathbf{P S A}=$ prostate specific antigen; $\mathbf{P S A D}=$ prostate specific antigen density; $\mathbf{G S}=$ Gleason score .

level and the presence of prostate cancer. They showed the significant negative relationships between digit ratio and PSA level and the presence of prostate cancer. However, Jung et al. (11) did not find that the prostate biopsy findings were correlated to digit ratio because the number of prostate cancer patients in their study was not sufficient to reveal the relationship of digit ratio to the biopsy findings.

The histologic grade is the most important piece of information obtained from the needle biopsy. The Gleason grading system is the most commonly used classification scheme for the histologic grading of prostate cancer $(19,20)$. Gleason grade has been shown to correlate with the pathologic extent of disease (21-25). The presence of a Gleason pattern 4 or greater or a Gleason sum of 7 or greater is particularly predictive of a poorer prognosis. Numerous multi- variate analyses support the assertion that Gleason sum is a strong predictor of the extent of prostate disease $(22,23,26-28)$.

According to our data, only five patients had family history of prostate cancer (first-degree relative). At present, the screening of prostate cancer in Korea is not as widespread as in Western countries (29). Furthermore, among Korean men, prostate cancer accounts for $2.4 \%$ and $1.5 \%$ of the total cancer cases and deaths, respectively $(30,31)$. Also, age-adjusted incidence and mortality rates of prostate cancer in Korea are much lower than those in most Western nations (32). Therefore, it is unusual that the prostate biopsy patients have family history of prostate cancer.

In the present study, besides age, PSA and DRE, univariate and multivariate analysis using logistic regression model showed that digit ratio is also an independent predictor of prostate can- 
Table 5 - Comparison of the positive cores between the two studied groups.

\begin{tabular}{|c|c|c|c|c|c|}
\hline & & $\begin{array}{c}\text { Digit ratio } \\
<0.95\end{array}$ & $\begin{array}{c}\text { Digit ratio } \\
\geq 0.95\end{array}$ & $p$-value & $\begin{array}{c}\text { OR } \\
(95 \% \mathrm{Cl})\end{array}$ \\
\hline No of positive cores & & 282 & 126 & & \\
\hline$\%$ core cancer vol & & $46.69 \pm 31.73$ & $37.07 \pm 29.43$ & 0.005 & \\
\hline No of cores & 4 & 8 & 1 & 0.140 & \\
\hline \multirow[t]{7}{*}{ with sum of GS } & 5 & 3 & 2 & & \\
\hline & 6 & 86 & 42 & & \\
\hline & 7 & 111 & 55 & & \\
\hline & 8 & 56 & 25 & & \\
\hline & 9 & 18 & 1 & & \\
\hline & $\leq 8$ & 264 & 125 & 0.010 & $\begin{array}{c}8.523 \\
(1.125-64.562)\end{array}$ \\
\hline & $\geq 9$ & 18 & 1 & & \\
\hline \multirow[t]{6}{*}{ No of cores with primary GS } & 2 & 8 & 1 & 0.042 & \\
\hline & 3 & 153 & 67 & & \\
\hline & 4 & 109 & 58 & & \\
\hline & 5 & 12 & 0 & & \\
\hline & $\leq 4$ & 270 & 126 & 0.021 & $\begin{array}{c}1.044 \\
(1.019-1.070)\end{array}$ \\
\hline & 5 & 12 & 0 & & \\
\hline \multirow[t]{4}{*}{ No of cores with secondary GS } & 2 & 11 & 3 & 0.150 & \\
\hline & 3 & 135 & 74 & & \\
\hline & 4 & 128 & 48 & & \\
\hline & 5 & 8 & 1 & & \\
\hline
\end{tabular}

$\%$ = percentage; Digit ratio = 2nd digit length $/$ 4th digit length; $\mathbf{G S}=$ Gleason score.

cer detection (Table-2). Therefore, it can be suggested that digit ratio is associated with prostate cancer risk.

One of the novel findings of this study was that digit ratio is related to the cancer detection rate and the aggressiveness (high percentage of core cancer volume and high Gleason score) of prostate cancer.
To date, only three studies have investigated the relationship between digit ratio and prostate cancer risk $(11,18,33)$. Two studies have reported a strong association between 2D:4D and risk of prostate cancer $(11,18)$. In the other study, although it is weak, an inverse association was observed between 2D:4D and risk of prostate cancer for patients aged < 60 (33). However, these studies did 
Table 6 - Comparison of the positive cores with GS $\geq 7$ between the two studied groups.

\begin{tabular}{|c|c|c|c|c|}
\hline & & $\begin{array}{c}\text { Digit ratio } \\
<0.95\end{array}$ & $\begin{array}{c}\text { Digit ratio } \\
\geq 0.95\end{array}$ & $p$-value \\
\hline No of positive cores & & 185 & 81 & \\
\hline \% core cancer vol. & & $57.57 \pm 30.24$ & $40.27 \pm 29.95$ & 0.000 \\
\hline Sum of GS & & $7.5 \pm 0.7$ & $7.3 \pm 0.5$ & 0.028 \\
\hline Primary GS & & $3.7 \pm 0.6$ & $3.7 \pm 0.5$ & 0.965 \\
\hline Secondary GS & & $3.8 \pm 0.5$ & $3.6 \pm 0.5$ & 0.020 \\
\hline \multirow[t]{3}{*}{ No of cores with sum of GS } & 7 & 111 & 55 & 0.044 \\
\hline & 8 & 56 & 25 & \\
\hline & 9 & 18 & 1 & \\
\hline \multirow[t]{3}{*}{ No of cores with Primary GS } & 3 & 64 & 23 & 0.025 \\
\hline & 4 & 109 & 58 & \\
\hline & 5 & 12 & 0 & \\
\hline
\end{tabular}

$\%=$ percentage; Digit ratio = 2nd digit length $/ 4$ th digit length; GS = Gleason score .

not reveal the relationship between digit ratio and cancer detection rate and cancer aggressiveness.

In our study, despite similar biopsy rates (22.4\% vs. $20.6 \%, p=0.544)$, lower digit ratio group had a higher cancer detection rate than higher digit ratio group ( $46.8 \%$ vs. $23.6 \%, \mathrm{p}=0.002$; OR $=$ 2.847, 95\% CI = 1.445-5.610) (Table-3).

Furthermore, when we analyzed the 408 positive biopsy cores (group A: digit ratio < 0.95, $\mathrm{n}=282$; group $\mathrm{B}$ : digit ratio $\geq 0.95, \mathrm{n}=126$ ), lower digit ratio group had a higher percentage of core cancer volume than higher digit ratio group $(46.69 \pm 31.73 \%$ vs. $37.07 \pm 29.43 \%, p=0.005)$ (Table-5). Also, a significantly greater proportion of cores were found to have sum of Gleason score $\geq 9(18 / 282(6.4 \%)$ vs. $1 / 126(0.8 \%), p=0.010)$ and primary Gleason score $=5(12 / 282(4.3 \%)$ vs. $0 / 126(0.0 \%), p=0.021)$ in lower digit ratio group (Table-5).

In other words, most of the positive cores with sum of Gleason score $\geq 9$ or all the positive cores with primary Gleason score $=5$ were found in the group with a lower digit ratio rather than in the group with a higher digit ratio. These results suggest that digit ratio may predict the histologic grade as well as the cancer detection rate on prostate biopsy. We think that this is very important and it can be highly suggestive of the relationship between digit ratio and cancer aggressiveness.

According to our data, we have found that the prostate biopsy findings of each cancer patient were not related to digit ratio (Table-4). Actually, the total number of patients who had prostate cancer was 61 . So, we think that the number of prostate cancer patients was not sufficient to reveal the relationship of digit ratio to the biopsy findings of the patients. However, when we considered the prostate biopsy findings of each positive core, the prostate biopsy findings of the positive cores were related to digit ratio (Tables 5 and 6). Since the total number of positive cores was 408 , we think that this number is sufficient to reveal the relationship of digit ratio to the biopsy findings.

Our results show that the positive cores of the patients with a lower digit ratio have a higher percentage of core cancer volume and that a significantly greater proportion of cores with a lower digit ratio have a high Gleason score. Concluding, 
digit ratio may be related to the histologic grading of prostate cancer and the extent of disease.

Digit ratio is reflective of prenatal androgen exposure and the in utero milieu. Our results show that digit ratio is related to prostate cancer, like was shown by the study of Jung et al. (11). This can be one of the evidences that prenatal androgen exposure (the in utero milieu) may be related to the later development of prostate cancer, which was already proposed by Henderson et al. (34) in 1988.

\section{CONCLUSIONS}

Our results showed that a lower digit ratio is related to an increasing probability of detection of prostate cancer, a high percentage of core cancer volume and a high Gleason score. These findings mean that patients with a lower digit ratio have a higher chance of developing prostate cancer and they might have more aggressive prostate cancer.

\section{CONFLICT OF INTEREST}

None declared.

\section{REFERENCES}

1. Garn SM, Burdi AR, Babler WJ, Stinson S: Early prenatal attainment of adult metacarpal-phalangeal rankings and proportions. Am J Phys Anthropol. 1975;43: 327-32.

2. Kondo T, Zákány J, Innis JW, Duboule D: Of fingers, toes and penises. Nature. 1997; 390: 29.

3. Mortlock DP, Innis JW: Mutation of HOXA13 in hand-footgenital syndrome. Nat Genet. 1997; 15: 179-80.

4. Phelps VR: Relative index finger length as a sex-influenced trait in man. Am J Hum Genet. 1952; 4: 72-89.

5. Peters M, Mackenzie K, Bryden P: Finger length and distal finger extent patterns in humans. Am J Phys Anthropol. 2002; 117: 209-17.

6. Manning JT, Scutt D, Wilson J, Lewis-Jones DI: The ratio of 2nd to 4th digit length: a predictor of sperm numbers and concentrations of testosterone, luteinizing hormone and oestrogen. Hum Reprod. 1998; 13: 3000-4.

7. Lutchmaya S, Baron-Cohen S, Raggatt P, Knickmeyer R, Manning JT: 2nd to 4th digit ratios, fetal testosterone and estradiol. Early Hum Dev. 2004; 77: 23-8.
8. Manning JT, Bundred PE, Newton DJ, Flanagan BF: The second to fourth digit ratio and variation in the androgen receptor gene. Evol Hum Behav. 2003; 24: 399-405.

9. Giovannucci E, Stampfer MJ, Krithivas K, Brown M, Dahl D, Brufsky $A$, et al.: The CAG repeat within the androgen receptor gene and its relationship to prostate cancer. Proc Natl Acad Sci U S A. 1997 1; 94: 3320-3. Erratum in: Proc Natl Acad Sci U S A 1997; 94: 8272.

10. Stanford JL, Just JJ, Gibbs M, Wicklund KG, Neal CL, Blumenstein $\mathrm{BA}$, et al.: Polymorphic repeats in the androgen receptor gene: molecular markers of prostate cancer risk. Cancer Res. 1997 15; 57: 1194-8.

11. Jung H, Kim KH, Yoon SJ, Kim TB: Second to fourth digit ratio: a predictor of prostate-specific antigen level and the presence of prostate cancer. BJU Int. 2011; 107: 591-6.

12. Scutt D, Manning JT: Symmetry and ovulation in women. Hum Reprod. 1996; 11: 2477-80.

13. Manning JT: Fluctuating asymmetry and body weight in men and women: Implications for sexual selection. Ethol Sociobiol. 1995; 16: 145-53.

14. Voracek M, Manning JT: Length of fingers and penis are related through fetal Hox gene expression. Urology. 2003; 62: 201.

15. Robinson SJ, Manning JT: The ratio of 2 nd to 4 th digit length and male homosexuality. Evol Hum Behav. 2000; 21:333-45.

16. Manning JT, Callow M, Bundred PE: Finger and toe ratios in humans and mice: implications for the aetiology of diseases influenced by HOX genes. Med Hypotheses. 2003; 60: 340-3.

17. Williams TJ, Pepitone ME, Christensen SE, Cooke BM, Huberman $A D$, Breedlove NJ, et al.: Finger-length ratios and sexual orientation. Nature. 2000; 404: 455-6.

18. Rahman AA, Lophatananon A, Stewart-Brown S, Harriss D, Anderson J, Parker T, et al.: Hand pattern indicates prostate cancer risk. Br J Cancer. 2011; 104: 175-7.

19. Gleason DF: Classification of prostatic carcinomas. Cancer Chemother Rep. 1966; 50: 125-8.

20. Narain V, Bianco FJ Jr, Grignon DJ, Sakr WA, Pontes JE, Wood DP Jr: How accurately does prostate biopsy Gleason score predict pathologic findings and disease free survival? Prostate. 2001; 49: 185-90.

21. Stein A, deKernion JB, Dorey F: Prostatic specific antigen related to clinical status 1 to 14 years after radical retropubic prostatectomy. Br J Urol. 1991; 67: 626-31.

22. Epstein JI, Carmichael MJ, Pizov G, Walsh PC: Influence of capsular penetration on progression following radical prostatectomy: a study of 196 cases with long-term follow-up. J Urol. 1993I; 150: 135-41.

23. Epstein JI, Pizov G, Walsh PC: Correlation of pathologic findings with progression after radical retropubic prostatectomy. Cancer. 1993; 71: 3582-93.

24. Partin AW, Pound CR, Clemens JQ, Epstein JI, Walsh PC: Serum PSA after anatomic radical prostatectomy. The Johns Hopkins experience after 10 years. Urol Clin North Am. 1993; 20: 713-25.

25. Zincke H, Oesterling JE, Blute ML, Bergstralh EJ, Myers RP, Barrett DM: Long-term (15 years) results after radical prostatectomy for clinically localized (stage T2c or lower) prostate cancer. J Urol. 1994; 152: 1850-7. 
26. Epstein JI, Walsh PC, Brendler CB: Radical prostatectomy for impalpable prostate cancer: the Johns Hopkins experience with tumors found on transurethral resection (stages $\mathrm{T} 1 \mathrm{~A}$ and $\mathrm{T} 1 \mathrm{~B}$ ) and on needle biopsy (stage $\mathrm{T} 1 \mathrm{C}$ ). J Urol. 1994; 152: 1721-9.

27. Epstein JI, Walsh PC, Carmichael M, Brendler CB: Pathologic and clinical findings to predict tumor extent of nonpalpable (stage T1c) prostate cancer. JAMA. 1994; 271: 368-74.

28. Ferguson JK, Bostwick DG, Suman V, Zincke H, Oesterling JE: Prostate-specific antigen detected prostate cancer: pathological characteristics of ultrasound visible versus ultrasound invisible tumors. Eur Urol. 1995; 27: 8-12.

29. Hong SK, Yu JH, Han BK, Chang IH, Jeong SJ, Byun SS, et al.: Association of prostate size and tumor grade in Korean men with clinically localized prostate cancer. Urology. 2007; 70: 91-5.

30. Shin HR, Won YJ, Jung KW, Kong HJ, Yim SH, Lee JK, et al.: Nationwide cancer incidence in Korea, 1999 2001; first result using the national cancer incidence database. Cancer Res Treat. 2005; 37: 325-31.
31. Korea National Statistical Office: The cause of death statistics, 1983-2003. Korea, 2005.

32. Sim HG, Cheng CW: Changing demography of prostate cancer in Asia. Eur J Cancer. 2005; 41: 834-45.

33. Muller DC, Giles GG, Manning JT, Hopper JL, English DR, Severi G: Second to fourth digit ratio (2D:4D) and prostate cancer risk in the Melbourne Collaborative Cohort Study. $\mathrm{Br}$ J Cancer. 2011; 105: 438-40.

34. Henderson BE, Bernstein L, Ross RK, Depue RH, Judd HL: The early in utero oestrogen and testosterone environment of blacks and whites: potential effects on male offspring. $\mathrm{Br}$ J Cancer. 1988; 57: 216-8.

Correspondence address:

Dr. Tae Beom Kim

Department of Urology

Gachon University Gil Hospital

1198 Guwol-Dong, Namdong-Gu Incheon 405-760, Korea

Fax: + 8232 460-8340

E-mail: uroclinic@naver.com 